\title{
Geometric and Dynamic Application of Satellite Geodesy in Environmental Mapping: A Conceptual Review
}

\author{
Hart L. ${ }^{1, *}$, Oba T. ${ }^{1}$ and Babalola A. ${ }^{2}$ \\ ${ }^{1}$ Department of Surveying and Geomatics, Rivers State University, Port Harcourt, Nigeria \\ ${ }^{2}$ Department of Surveying and Geoinformatics, University of Ilorin, Ilorin, Nigeria \\ *Corresponding Author: lawrence.hart@ust.edu.ng
}

https://doi.org/10.36263/nijest.2019.02.0153

\begin{abstract}
The impacts of satellite geodesy are being felt in all aspects of human development and environmental management. Its principal advantages stem from the global nature of its scope, the diversity of its sensors and the realtime capabilities to capture both visual, numerical and other data types for as long as desired and in all weather conditions. The capacity to pinpoint locations to high precision in fractions of a second and provide detailed geometric and graphical definitions of large swaths are proving useful for meeting the needs of a people desirous for automation in all aspects of human endeavours and for confronting the increasing challenges of sustainable development and environmental degradation. The most innovative facility provided by satellite geodesy is the technology of remote sensing which enables measurements of objects without physical contact for interpretative and mensurative analysis and mapping in static or kinematic modes. The aim of this paper is to showcase the contributions of satellite geodesy to sustainable environmental management its basic concepts and a brief exploration of some of its applications. The overall objective is to underscore its critical role in socio-economic development. The paper posits therefore that today's rapidly changing environmental problems requiring static and realtime locational and graphical solutions can be solved through the facilities of satellite geodesy.
\end{abstract}

Keywords: Satellite, geodesy, dynamic, environment, geometric, technology.

\subsection{Introduction}

Traditional geodesy has been known to be a means of defining the physical features of the global earth in mathematical, numerical and graphical forms for purposes of understanding and portraying the geographical distribution of its resources and their influence on socio-economic development. The Global Navigation Satellite System (GNSS) and other types of satellite systems with diverse sensors constitute one of the most recent innovations of geodesy which when used in combination with the equally new and intelligent software packages that can manage large spatial data in both real time and offline modes, can support a wide range of innovative applications in environmental management with optimal precision.

Nonetheless, the application of satellite geodesy for mapping, positioning, navigation and sub-surface monitoring in emerging geodetic and geodynamical problems has created a wide range of need for geodata integration. For instance, the use of the GNSS for navigation or tracking on the earth or near the earth surface requires accurate positions to be supplied to a software package that can process map-based data in realtime - an activity that requires data integration. Routinely, numerous data sets such as geographical coordinates, time, earth rotational velocity, polar motion parameters etc., need to be integrated for spatial data analysis tasks, which may include among other things: to investigate environmental change, manage national security and contribute to hazard mitigation and emergency management (Fubara, 2011). Mapping the environment has always been an intricate exercise in the face of its changing nature and attributes through climate change, geodynamical phenomena, human 
and anthropogenic activities with emerging challenges in methodology, instrumentation and skill gap required.

Yet, it is pertinent to note that Satellite geodetic outputs are not only contributing to our appreciation of the earth, but they also benefit many societal activities, ranging from disaster prevention and mitigation to the protection of the biosphere and the environment. Therefore, geodesy contributes in countless ways to increased security, a better use of natural resources and, ultimately, to achieving the goal of sustainable development on our fragile planet.

Theoretically, Satellite geodesy is based on the observation of artificial earth satellites, natural celestial bodies (moon) and other extra-galactic radio sources enclosed in a defined orbital path with its associated orbital parameters. Directions range and range-rates are determined between earth surface location and the satellite or between satellites. Some measurements, for instant accelerations, are taken within the satellites themselves.

The thrust of this work is to review and bring to the fore the relevant basic conceptual and mathematical models which underpin the operations of satellite geodesy; the geometric and dynamic nature of its practical realizations which enable it to create solutions to emerging human and environmental challenges are also introduced. The work is also to dispel the commonly held narrow view of geodesy as a discipline that only provides the size, shape and gravity field of the earth by demonstrating the huge relevance and wide applicability of satellite geodesy in the geoscience and engineering solutions of resource mapping, exploitation and position-dependent measurement, calculation, analysis including visualization studies.

The need to have a better and deep understanding of the theoretical frame and the practical demonstration of the science of satellite geodesy in all of its ramification is urgent and strong. This will go a long way to stimulate and deploy its capability to confront the emerging environmental issues in its existential and/or developmental form. Secondly, and in addition, to its adaptability to modern technology and its potential to be practiced within the confines of contemporary technology, it will stimulate interest to upcoming scholars and policy managers to understand the infinite strength of satellite geodesy in geosolution provision to our environment.

\subsection{Overview of Satellite Geodesy}

Geodesy from a general perspective and aptly captured by Agajelu, (2018); is the scientific discipline that deals with the determination of the exact figure and the external gravity field of the earth and their variations with time, as well as, the mean earth ellipsoid, using terrestrial and extra-terrestrial observations. It demonstrates the application of determining the size, shape of the entire earth, dimensions as well as location of points on it. It enables the actual representation of the earth as a geometric figure that is supported by an equatorial radius, flattening of the figure, in addition to equatorial and polar gravity. In practice, we have different approaches in demonstrating the applicability of geodesy as a geosolution discipline of which the satellite or space geodesy has become a veritable approach. Satellite geodesy comprises the observational and computational technique which allows the solution of geodetic and geodynamical problems by the use of precise measurement to, from, or between artificial satellites, mostly near-earth, satellites. In relation to Helmert's classical definition (1880) of geodesy, which is basically still valid, the objectives of satellite geodesy are today mainly considered in an efficient way as indispensable to virtually all human sphere for socio-economic development, space science and technology, (Fubara, 2006). This branch of geodesy adopts observations connecting points on the earth's surface to dynamic or stationary spatial points and uses the theories of celestial mechanics, dynamical and spherical astronomy to fix the points in space and on the earth surface. They also include, because of the increasing observational accuracy, time-dependent variations which impacts on various astrodynamical, geological and geophysical processes affected by gravity on the earth or near the earth surface. These associated applications underscores the usefulness of the capabilities of this branch of 
geodesy: the determination of geometrical 3-dimensional positions and velocities in global, regional and local reference frames, the determination of the earth's gravity field and its temporal variations and modelling and observing of geodynamical phenomena (tectonic plates, loading crustal deformations) including the rotation and orientation of the earth (polar motion, length of day, precession and nutation. In addition, the orientation of the earth's axis and its rotation speed and time with respect to length of day, designated as earth's rotation. (Fubara, 2006)

The use of satellite geodesy has some prerequisites; these are basically a comprehensive knowledge of the satellite motion under the influences of all acting forces as well as the description of the positions of the satellites, orbital parameters and ground stations in suitable references frames. This method is an accurate means of relative-position determination of points on the earth's surface as shown in figure 1, which are separated by thousands of kilometres. It is the most powerful means of preciseposition fixation, air, land, sea navigation capability and precise timing on a global scale. It also serves as an indispensable tool in the oil and gas industry, mapping of socio-economic development, telecommunication activities, satellite orbit determination and tracking of space borne vehicles.

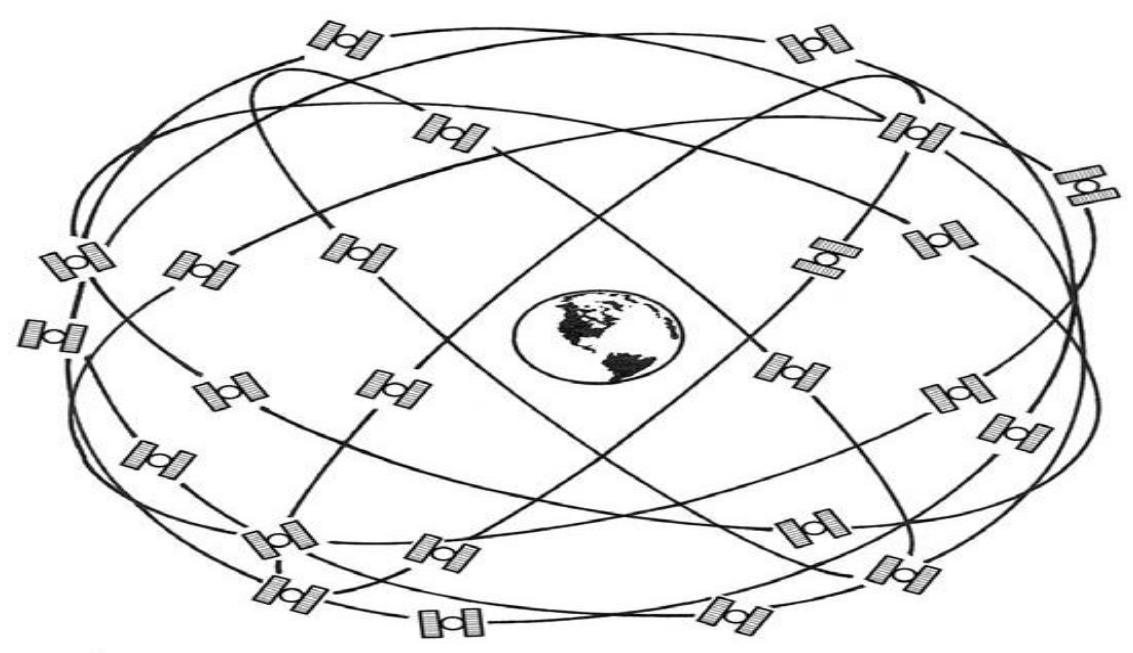

Figure 1: The global positioning system (GPS), 24 satellites configuration

The results of geodetic- astronomic, space-based gravimetric observations are used within the field of astronomy and physical geodesy for the determination of the gravity field of the earth (Torge, 1991).

\subsection{An overview of theoretical and mathematical framework of satellite geodesy}

The fundamental frame on which satellite geodesy is premised is in relation to the concept of the perturbed orbit and its attendant orbital motion influenced by the spherical symmetric earth's gravitational attraction as well as other forces acting on the satellite. It supposes the remaining portion of the satellite orbit that recognizes the effect of the luni-solar gravitation, atmospheric drag, solar radiation pressure, earth-tide and ocean tide effect and such like. In another vein, the normal orbit determination which is referred to as the two-body problem which assumes that there are only the earth and the satellite in space. This can be solved analytically if they are represented in elliptical elements, thereby providing complete solution for a space fixed orbit. (King et al., 1985; Agajelu, 2018)

The Kepler's laws describe the satellite's orbit as an ellipse with the geocenter at one of the foci, which means the satellite and its geocenter are on the same plane, similarly the geocenter-satellite straight line sweeps out area in equal time and finally, the square of the mean motion of the satellite is inversely proportional to the cube of the average distance of the satellite from the geocenter. These laws underscore the theoretical frame for which the satellite orbits are modelled and determined 
within the Newtonian principles of motion and attraction. Hence, the following mathematical models give insight on the satellite behaviour:

i. To know the size and shape of the satellite orbit and the position of the earth in the ellipse (Smart, 1960; Escobal, 1965; Leick 1995; Agajelu, 2018).

$$
r=\frac{a\left(1-e^{2}\right)}{1+e \cos f}
$$

Where, $r$ is radius vector of satellite (i.e. geocenter-satellite distance); e is Eccentricity of the orbit; $f$ is true anomaly and a is semi-major axis of the orbital ellipse.

ii. To indicate the speed of satellite when close or far from the earth. The radius vector sweeps out areas at constant rate.

$$
A=\frac{d A}{d t}=\frac{1}{2} \sqrt{G m a\left(1-e^{2}\right)}=k
$$

Where, $\mathrm{A}$ is area rate $(\mathrm{dA}), \mathrm{dt}$ is change in Area \& Time; $\mathrm{m}$ is mass of body; a is acceleration; $\mathrm{G}$ is gravitational constant.

iii. To determine the average motion of the satellite along its orbital path.

$$
n^{2} \alpha \frac{1}{a^{3}}
$$

If geocentric gravitational constant, GM to be the constant of proportionality, then Equation 3 can be written as:

$$
n^{2} a^{3}=G M
$$

where, $\mathrm{n}$ is mean motion in radians.

$$
n=\frac{D}{(T)}
$$

Where, $\mathrm{D}$ is total distance of the circumference; $\mathrm{T}$ is period

$$
a=\frac{d_{1}+d_{2}}{2}
$$

Where, $d_{1}$ is distance to apogee; $d_{2}$ is distance to perigee.

$$
T=\left(\frac{4 \pi^{2} a^{3}}{G M}\right)^{\frac{1}{2}}
$$

The equation of motion of a satellite

$$
\vec{F}=m a
$$

Where, $\vec{F}$ is force acting on a body; $\mathrm{m}$ is mass of satellite (body); a is acceleration of the body.

If Equation 5 is expressed in terms of position vector and time, then we can represent the equation as: 


$$
\vec{F}=m \frac{d^{2} \vec{r}}{d t^{2}}
$$

where,

$$
a=\frac{d^{2} \vec{r}}{d t^{2}}=\vec{r}
$$

The essential value of the satellite is that it is a moving body within Earth's gravity field. This view leads to the dynamical method of satellite geodesy. In dynamical satellite geodesy orbital arcs of different lengths are considered in view of the short time of data tracking, relative position of observing stations can be determined and corresponding orbital elements of each passing satellite. When arc lengths between a few minutes and up to several revolutions around earth are used, we speak of short arc techniques; the term for the use of longer arcs, up to around 30 days and more, is long arc techniques. The orbits are described in suitable geocentric reference frames, determination of zonal harmonics required to model the perturbations caused by the earth's gravitational field on the orbital path of the satellite (Vaníc $`$ ek and Krakiwsky, 1986; Wolf and Ghilani, 2006).

\subsection{Applications of Satellite Geodesy}

\subsection{Acquiring data for DTM creation}

Digital Terrain Model (DTM), is a digital representation of the terrain surface using a set of heights over 2D points residing on a reference surface. In other words, it approximates a part or the whole of the continuous terrain surface by a set of discrete points with unique height values over $2 \mathrm{D}$ points (Hirt, 2015).

Digital Terrain Models (DTM) plays a pivotal role in diverse disciplines. Its application can be greatly felt in planning of engineering structures such as roads, railways, canals, large reservoirs, hydro dams, rendering visualisations, topographic and thematic maps. In gravity field modelling and physical geodesy, it provides geometry information of the topographic masses. DTM is based on topographical information which is commonly obtained by classical terrestrial survey. However, the process of data acquisition of the terrestrial survey is costly, time consuming, tedious and poses a greater challenge of intervisibility between stations. To this effect, the technology of GNSS in satellite geodesy can be deployed in acquiring accurate data for high-resolution DTM creation using the real-time kinematic method of Global Positioning System (GPS) based on either a reference global and/or local geoid model. The GPS does not only provide the 3-dimensional geographical $(\varphi, \lambda, h)$ and/or projected coordinates in UTM $(\mathrm{E}, \mathrm{N}, \mathrm{h})$ which may be transformed to the earth-fixed centered cartesian coordinate $(\mathrm{x}, \mathrm{y}, \mathrm{z})$ information needed for the DTM creation but offers an ease, quick and comparatively cheap alternative as less personnel are needed for the survey and intervisibility between stations are not required. Figure 2 shows a 2-dimensional representation of topographic characteristics of part of the environment identifying relative positions of natural and cultural features. It describes space features and vegetation as depicted. Similarly, Figure 3, depicts a 3-dimensional terrain model with contour. This is a critical geospatial information required for sustainable engineering design and environmental management. 


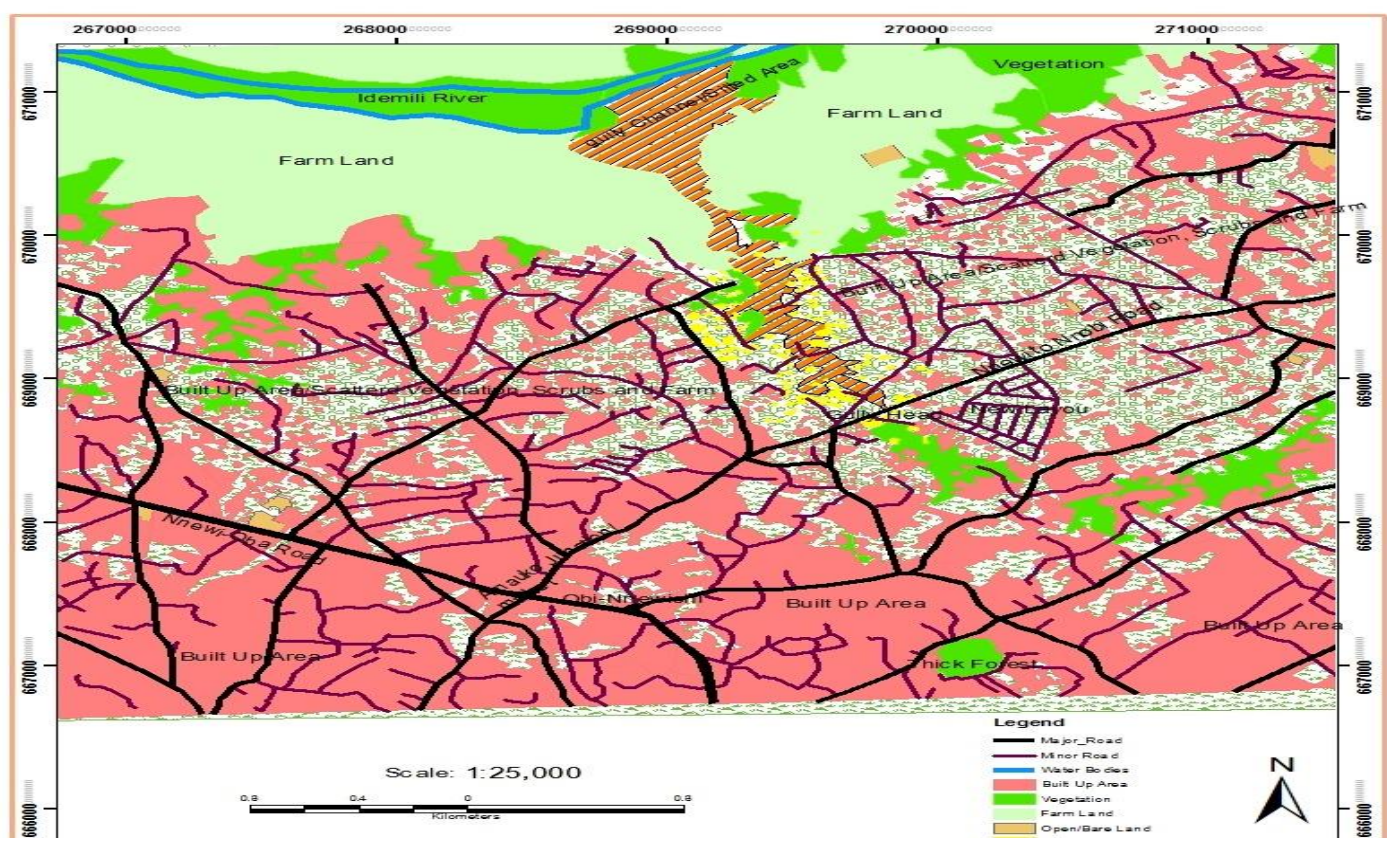

Figure 2: Map showing topographic characteristics of part of the environment (Source: Ezeomedo et al, 2017)

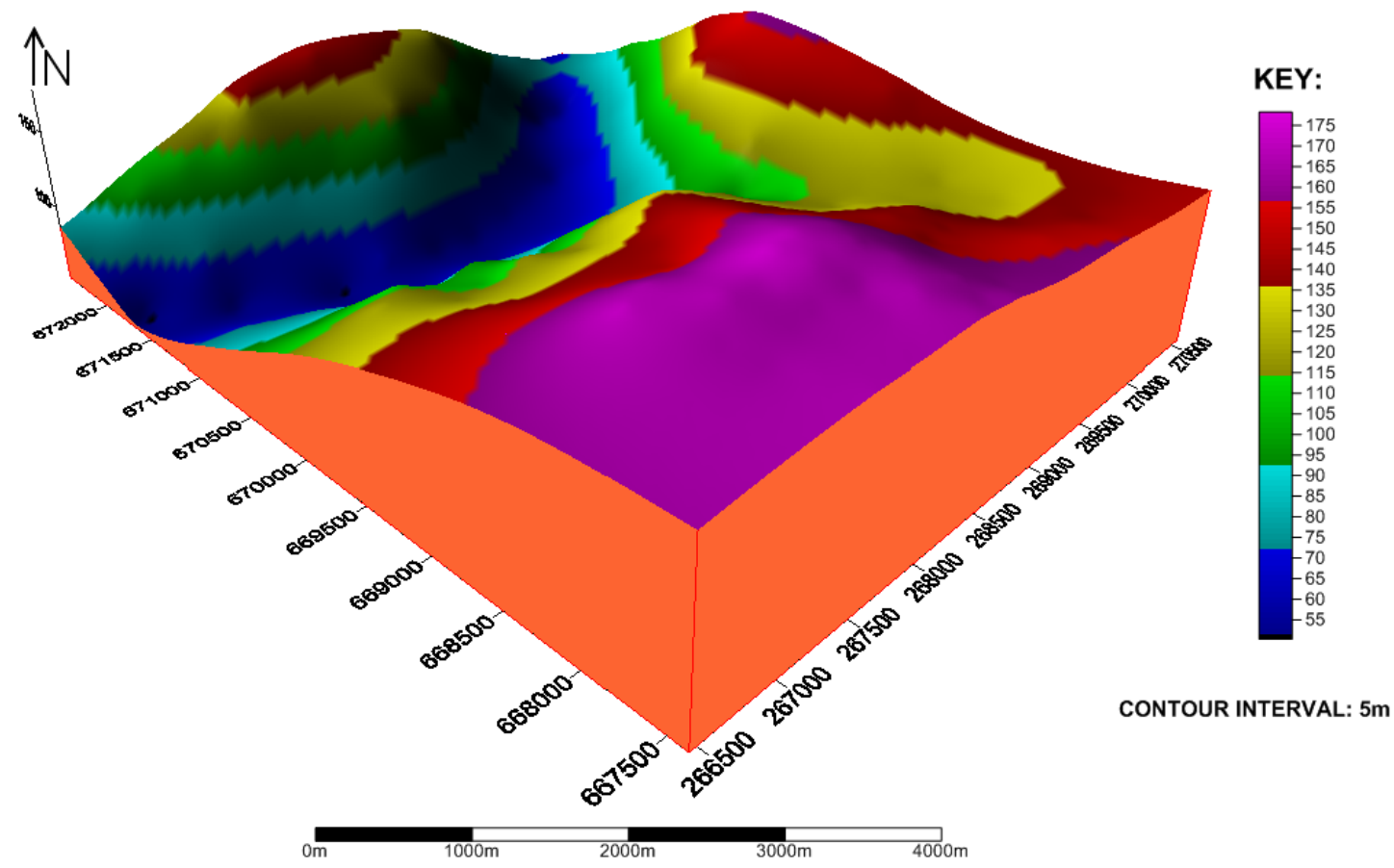

Figure 3: DTM Model. (Source: Katarzyna, 2009) 




Figure 4: DTM with contours. (Source: Katarzyna, 2009)

\subsection{Oil and Gas platform deformation monitoring}

Platforms are built around onshore and offshore oil and gas natural reservoirs. As a result of continued extraction and exploration of oil and gas from these reservoirs, the reservoirs could start depleting due to lack of pore pressure and this in turn could result to platform deformation (subsidence). If the rate at which the subsidence occurs is not monitored and a control measure put in place, it could lead to disaster (Fubara, 2011). Hence, this subsidence information becomes imperative as to assess its risk level and safety requirements in that a possible disaster could arise from such situation. Through the use of GNSS (GPS) technology, reliable and accurate information of subsidence on the platform can be achieved. Figure 6 shows an offshore location of an oil drilling facilities that undergoes subsidence. Other allied applications of satellite geodesy include rig movement and positioning, geohazard mapping in offshore locations, prospecting and exploration activities. Furthermore, Differential Synthetic Aperture Radar Interferometry (DInSAR) is one of the most used remote sensing techniques for the investigation of Earth's surface deformation phenomena, (Massonnet and Feigl, 1998). It permits the retrieval of surface deformation maps with centimeter to millimeter accuracy, starting from the phase difference (Interferogram) of SAR image pairs relevant to the same area of interest but acquired at different epochs and with a significantly small orbital spatial separation (baseline) (Okeke and Moka, 2004; Okeke, 2005)

The change in the phase shift $\Delta \varphi$ can be expressed in the form of the following simple equation:

$$
\Delta \phi=\frac{\Delta \pi}{\lambda} \Delta R+\alpha
$$

Where $\lambda$ is the wavelength, $\Delta R$ is the displacement, $\alpha$ is a phase shift due to different atmospheric conditions at the time of the two Radar acquisitions. As a consequence, any displacement of a Radar target along the satellite line of sight creates a phase shift in the Radar signal that can be detected by comparing the phase values of two SAR images acquired at different times (Okeke and Moka, 2004; Okeke, 2005). 


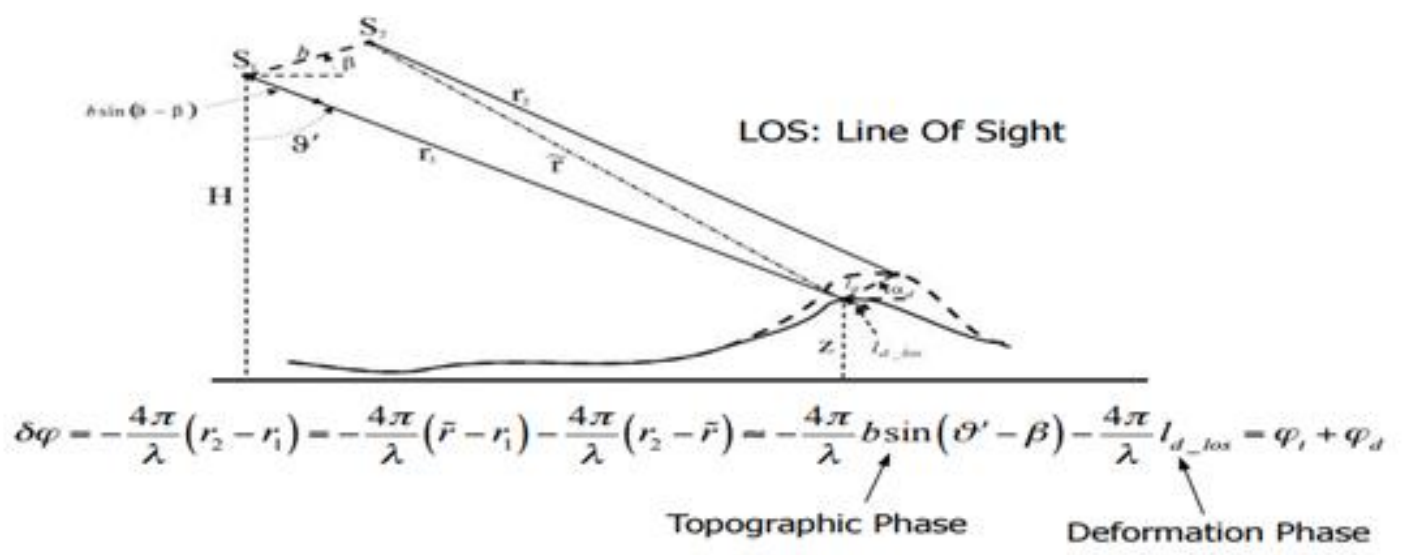

Figure 5: Differential SAR Interferometry (DInSAR) (Casu et al., 2016)

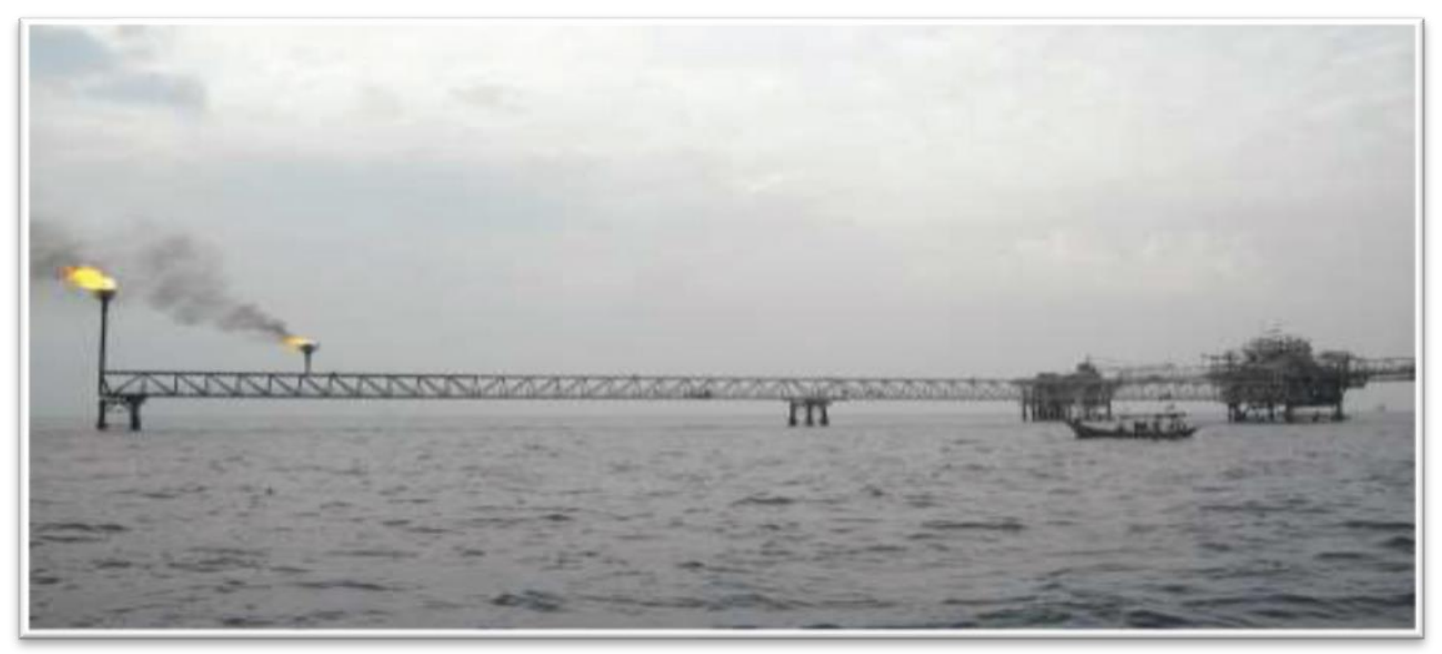

Figure 6: Offshore oil and gas platform (Source: Heri, et al, 2018)

Similarly, Figure 7 shows a crude oil storage tank undergoing subsidence monitoring using laser scanning technology. This process indicates deviations axially horizontally and vertically over a period of time in the event of loading or changes in the earth crust. The current methodology is to use a total station to measure the position of pre-fixed studs around the top and bottom of a storage tank. The advantage of laser scanning is that instead of measuring a limited number of pre-defined points, the whole surface of the storage tank can be analysed at all levels - rather than just at the top and bottom of the tank. The environmental monitoring of these storage facilities underscores environmental sustainability through the principles of ground-based remote sensing which are being used in real time as an attribute of satellite geodesy, (Hart et al., 2018). 




Figure 7: Scan view of oil storage tank subsidence monitoring (Hart et al., 2018)

The advantages of using GNSS (GPS) survey method is that it provides the three-dimensional displacement vector with two horizontal and one vertical components, so it will give not only land subsidence information but also land motion in horizontal direction; it provides the displacement vectors in a unique coordinate reference system, so it can be used to effectively monitor land subsidence in a relatively large area like in offshore oil and gas field; this space-based measurement techniques can yield the displacement vectors with a several millimetre precision level which is relatively consistent in temporal and spatial domain, so it can be used to detect even a relatively small subsidence signal; and the GPS can be utilized in a continuous manner, day and night, independent of weather condition, so its field operation can be flexibly optimized (Heri et al., 2018).

Furthermore, the phenomenon of land subsidence and crustal motion has received a great deal of attention, since it can have a wide range of negative consequences, such as oil well failures, damage to surface infrastructures, or impact on the environment. Okeke et al, (2018) asserts that in the context of space-borne geodetic techniques, Differential Synthetic Aperture Radar Interferometry (DInSAR) has been considered as an efficient and cost-effective technique for monitoring land subsidence due to its large spatial coverage and high accuracy provided and in different conditions and scenarios, both natural and anthropogenic.

\subsection{Early warning for natural hazard}

Natural hazards such as tremors, earthquakes, volcanic eruptions and tsunamis occur as a result of earth crust deformation due to the expansion and contraction of the fault plain. Recent tremors in Mbape in Abuja, Igbogene in Bayelsa and other locations in north central and south west locations in the country underscore the need to deploy satellite techniques to monitor and determine its extent in the event of occurrence. When this phenomenon occurs, it causes some devastating effect on the earth's surface. The magnitude of the effect can be determined using the satellite technique in combination with some seismological instrument to record the vibration of the waves that occur beneath the earth crust. To this end, the period between data acquisition and the distribution of the information obtained from such data becomes an important consideration. For quick, ease and precise acquisition of such data, GNSS (GPS) technology can be deployed to acquire data that can be used to rapidly determine earthquake location, size, and potential for damage. As a result of the physics of seismic wave generation and propagation, when seismologists sense any seismic activity, they cannot be determined if it is a small or large earthquake with seismic data alone but with real-time geodetic data, this can be determined. Figure 9 depicts modelling dynamics using Remote Sensing and Geospatial Information System (GIS) techniques which provide a platform for the prediction of earth crustal changes both at sea and on land. 



Figure 8: Environmental modelling using remote sensing and GIS technology (Adapted from Ezeomedo, et al (2017))

\subsection{Conclusion}

GNSS technology the operational component of satellite geodesy supports the efforts to understand and forecast changes in our environment by integrating GPS measurement into active methods used by scientist in the field of geodesy and geosciences to study the environment and its corresponding changes that occur over a long period of time, (Hart, 2015). The satellite and Remote Sensing technology have played a vital role in positioning and navigation application which has emerged as a fundamental component of geodetic infrastructure and services worldwide. These technologies have all weather capability, high temporal and spatial resolution and high accuracy. Areas where these technologies could be deployed includes; weather forecast, climate research, high technology agricultural projects, soil research, crustal motion and tectonic plate changes in real time. This has become imperative with the current trends of earth tremor in different parts of Nigeria. In another vein, atmospheric water content, an important component in terms of weather forecasts, can be accurately determined using this technology. Also, the proliferation of GPS tidal tracking site can improve the estimation of the vertical component of sites position from GPS measurement, which uniquely present an opportunity to directly observe the effects of ocean tides especially in the continental shelves and in particular the Niger Delta region of Nigeria.

Geometric and Dynamic Application of Satellite Geodesy applications in environmental mapping is well established in many countries. However, there has been low progress in its research and application in Nigeria. To stimulate a knowledge-based exploration of this new techniques in Nigeria, this paper presents a conceptual review of the application of GNSS technology as a technique of satellite geodesy in Environmental mapping. Its adaptability to contemporary technological changes is in the threshold of evolving as a discipline that is poised to solving earth related and emerging problems due to the interaction of man and the environment.

\section{References}

Agajelu S.I. (2018). Geodesy the Basic Theories-Classical and Contemporary, EL'DEMAK Publishing, Enugu.

Ayeni B. (2001). The Role of Geographic Information Systems in Environmental Impact Analysis (EIA) In Nigeria. A Conference Proceedings by the Centre for Environmental Protection and National Resources/Post Graduate School, UI, Ibadan and the Federal Ministry of Environment, Abuja, Nigeria. 
Bassey U. (2003). An Introduction to Geographic Information Technology. Tobistics Printing and Publishing Ventures, Oyo State.

Casu, F., Elefante, E., Imperatore, P., Zinno, I., Manunta, M., et al. (2014). "SBAS-DInSAR Parallel Processing for Deformation Time Series Computation", IEEE Journal of Selected Topics in Applied Earth Observation and Remote Sensing 7(8), pp 20-26

Casu, F., Manunta, M., \& Zinno, I. (2016). AGU 2015 Training on the SBAS-DInSAR web tool for Earth surface deformation analysis through the ESA Geohazard Exploitation Platform (online) Zenodo. http://doi.org/10.5281/zenodo.44624 (last accessed 10th October, 2017)

Dedi Atungal Sp, Bambang Kun Cahyono, and Abdul Nasir Matori (2014). Digital Terrain Modelling by Real Time Kinematic GPS. An unpublished lecture note, Department of Geodetic Engineering, Universitas Gadjah Mada, JI. Grafika no.2, 55281, Yogyakarta, Indonesia.

Escobal, P.R (1965). Methods of Orbit Determination. Wiley, New York

Ezeomedo I.C, Anukwonke C.C and Ono M.N (2017). Space Science and Technologies in Environmental Geodesy. A paper presented at the Nigeria Association of Geodesy General Assemble/Scientific Conference, Garden City 2017, Port Harcourt, Rivers State.

Francis I. Okeke, Nosa O. Alohan and Lawrence Hart (2018). Land Subsidence Mapping and Monitoring of Part of Niger Delta Region of Nigeria Using SBAS-DInSar Technique Within the ESA Geohazard Exploitation Platform (GEP). Nigerian Journal of Geodesy, vol 2(2), pp75-85

Fubara D.M.J. (2006). Improved Determination of Nigerian Geodetic Datum Transformation Parameters for Effective use of GPS. Quality Control Report for Shell Petroleum Development Company of Nigeria Limited, Port Harcourt.

Fubara, D.M.J., 2011. Space Geodesy in Coastal and Marine Environment. Union lecture, Nigeria Association of Geodesy 2011 Conference/ General Assembly, University of Nigeria Enugu, $14^{\text {th }}$ to $16^{\text {th }}$ September, 2011).

Hart, Lawrence; Udeh, Kenneth; Oba, Tamunobelema (2018). A Comparative Study of the Classical and High Definition Survey Approaches in Subsidence Monitoring of Crude Oil Storage Tanks. A Conference paper presented at the 54th Annual General Meeting (AGM) and Conference of the Nigerian Institution of Surveyors 17th to 21st June, 2019 at Awka, Anambra State.

Hart, L (2015). Development of Datum Transformation Procedure for Nigeria Based on National Transformation Version 2 (NTv2) Model. An Unpublished Ph.D Thesis, submitted to the Department of Geoinformatics and Surveying, University of Nigeria, Enugu Campus, Nigeria.

Heri Andreas, Hasanuddin Z. Abidin, Irwan Gumilar, Dina A. et al. (2018). The Use of GNSS GPS Technology for Offshore Oil and Gas Platform Subsidence Monitoring, in Multipurposeful Application of Geospatial Data edited by Rustam B. Rustamov IntechOpen Limited, London.

Hirt, C. (2015). Digital Terrain Models. In: Encyclopedia of Geodesy (Ed. E.W. Grafarend), Springer, Berlin, Heidelberg.

Jatau, B. (1990). Space Technology for Progress and the Environment. Workshop Proceedings of the Annual General Meeting and Conference of Nigerian Institution of Surveyors, Kano, Nigeria.

Katarzyna P. (2009). Analysis of Compilation Technology of Digital Terrain Model Based on Satellite, Tacheometric and Photogrametric Data. Lecture Notes in the Department of Surveying, University of Warmia and Mazury in Olsztyn.

King R. W, Masters, E.G, Rizos, C, Stolz, A. and Collins, J (1985). Surveying with GPS, Monograph 9, School of Surveying, University of New South Wales, Kensington, Australia.

Leick, A (1995). GPS Satellite Surveying $2^{\text {nd }} e d$. John Wiley \& Sons, Inc. New York 
Massonnet, D.; Feigl, K.L. (1998) Radar Interferometry and its application to changes in the Earth's surface. Rev. Geophys., 36(2), 441-500

Okeke, F. I. and Moka E. C. (2004). Detection and Monitoring of Land Subsidence caused by anthropogenic activities in Nigeria (Niger Delta) using InSAR Technique, Proceedings of the Nigerian Institution of Surveyors AGM, Conference, May 2004, Port Harcourt, Nigeria.

Okeke, F. I. (2005). Application of InSAR Techniques for Topographic Mapping and Earth Surface Deformation Monitoring for Nigeria, Nigerian Journal of Space Research, 1(1) pp 175 - 199.

Smart, W. M (1960). Spherical Astronomy. Cambridge University Press, London.

Torge, Wolfgang (1991). Geodesy $2^{\text {nd }}$ Ed, Walter de Gruyter Berlin. New York.

Vaníc ek, P., and E.J. Krakiwsky (1986). Geodesy: The Concepts. 2nd ed., Elsevier Science Publishers, Amsterdam, North Holland, Netherlands.

Wolf P.R. \& Ghilani C.D. (2006). Elementary Surveying: An Introduction to Geomatics. Pearson Prentice Hall, Pearson Education, Inc., United States of America.

\section{Cite this article as:}

Hart L., Oba T. and Babalola A., 2019. Geometric and Dynamic Application of Satellite Geodesy in Environmental Mapping: A Conceptual Review. Nigerian Journal of Environmental Sciences and Technology, 3(2), pp. 386-397. https://doi.org/10.36263/nijest.2019.02.0153 